\title{
Study on the Changes of Bone Marrow CD235a+ Nucleated Red Blood Cell Apoptosis and Signal Pathways in Patients with Chronic Altitude Sickness
}

\author{
YUANBIN YAO, YANMIN LIU ${ }^{1}$, AIBING WANG ${ }^{2}$, B. SUN ${ }^{3}$ AND YUQIONG DUAN ${ }^{4 *}$
}

Department of Emergency Medicine, ${ }^{1}$ Department of Cardiology, ${ }^{2}$ Department of Nephrology, ${ }^{3}$ Department of Intensive Medicine, ${ }^{4}$ Department of Anesthesiology, Qinghai Provincial People's Hospital, Xining, Qinghai 810007, China

Yao et al.: Changes of Bone Marrow CD235a+ Nucleated Red Blood Cell Apoptosis and Signal Pathways

\begin{abstract}
This study explored the changes in bone marrow CD235a+ nucleated red blood cell apoptosis and signal pathways in patients with chronic mountain sickness. We collected data from 21 chronic mountain sickness patients and 20 non-chronic mountain sickness patients. Bone marrow mononuclear cells, flow cytometry is used to detect the apoptotic index of CD235a+ nucleated red blood cells and to determine the changes in bone marrow CD235a+ nucleated red blood cell mitochondrial membrane potential; reverse transcription quantitative polymerase chain reaction was used to detect CD235a+ nucleated red blood cells, apoptosis related gene messenger RNA expression level, western blot was used to detect CD235a+ nucleated erythrocyte apoptosis-related protein expression level and compared the indicators between the two groups. Here, we found that the apoptosis of CD235a+ nucleated red blood cells in the bone marrow of chronic mountain sickness patients is negatively correlated with the accumulation of red blood cells. At the same time, the accumulation of red blood cells is positively correlated with the level of hemoglobin. The decrease of CD235a+ nucleated red blood cells in messenger RNA expression levels of apoptosis pathway indicates that the red blood cell apoptosis of chronic mountain sickness patients is related to the change of mitochondrial membrane potential and the reduction of the release of nuclear red blood cell apoptotic protein will also cause the decrease of CD235a+ nucleated red blood cell apoptosis.
\end{abstract}

Key words: Chronic mountain sickness, CD235a+ nucleated red blood cells, apoptosis, signaling pathways, mitochondrial membrane potential

Chronic Mountain Sickness (CMS) is also known as High Altitude Polycythemia (HAPC) ${ }^{[1-3]}$. It is a clinical syndrome characterized by excessive red blood cell proliferation, a significant increase in hemoglobin concentration and severe hypoxemia. The most prominent feature of CMS is the excessive accumulation of peripheral red blood cells and a significant increase in hemoglobin levels, which are prone to occur in people who migrate to the plateau ${ }^{[4]}$. High altitude hypoxia is the main cause of CMS patients. Studies believe that the main reasons for the decrease of CMS blood oxygen partial pressure include sleep disordered breathing and decreased hemoglobin-oxygen affinity ${ }^{[5,6]}$.

Under physiological conditions, there is a balance between red blood cell production and death and red blood cell accumulation occurs under pathological imbalance. Studies have shown that the increased proliferation of CMS red blood cells is related to the overexpression of hypoxia-inducible factors and the increase of circulating levels of Erythropoietin (EPO). However, there are few reports on its apoptosis at home and abroad ${ }^{[7]}$. Studies have shown that the apoptotic index of Bone Marrow Mononuclear Cells (BMMNCs) and cultured nucleated red blood cells in CMS patients decreases. It is speculated that the down-regulation of nucleated red blood cell apoptosis may be related to excessive red blood cells in $\mathrm{CMS}^{[8,9]}$. However, the pathway of CMS nucleated red blood cell apoptosis remains unclear. There are mainly two apoptosis signaling pathways and caspase-dependent pathways which are the main pathways: death receptor pathway and mitochondrial pathway. The death receptor pathway

*Address for correspondence

E-mail: 2843374471@qq.com 
(also known as the exogenous pathway) is initiated by the participation of transmembrane death receptors, Fas Cell Surface Death Receptor (Fas), Tumor Necrosis Factor Receptor (TNFR) and then binds to specific death ligands (Fas ligand (FasL), tumor necrosis factor (TNF) to produce biological responses downstream. Promote cell apoptosis; the apoptotic process of the mitochondrial pathway is the release of some factors in the mitochondria and then the mitochondrial Membrane Potential (MMP) is disintegrated. B-cell lymphoma 2 (Bcl-2) family proteins are important regulators of the mitochondrial extra-membrane potential ${ }^{[10-12]}$. Bcl-2 family proteins are divided into two categories. Among them, Bcl-2-associated X protein(Bax), BH3-interacting domain death agonist (Bid), Bcl-2 associated agonist of cell death (Bad), B-cell Lymphoma-extralarge (Bcl-xL) and Bcl-2 homologous antagonist/killer (Bak) promote cell apoptosis. However, caspase- 3 is considered to be an apoptotic protein ${ }^{[13-15]}$ and Myeloid cell leukemia 1 (Mcl-1) is involved in the regulation of mitochondrial division and fusion ${ }^{[16,17]}$.

As far as we know, there is no research report on the apoptosis signaling pathway of bone marrow nucleated red blood cells in patients with CMS. Therefore, based on the balance theory of cell physiology and metabolism and the preliminary research results of our team, this part of the study aims to explore the effect of apoptosis of nucleated red blood cells in the bone marrow on excessive erythrocytosis in patients with CMS and to evaluate the receptor pathway and receptors for nucleated red blood cell death in CMS patients, changes in mitochondrial pathway related factors.

\section{MATERIALS AND METHODS}

\section{General information:}

Research object: Inclusion criteria-The subjects of the study were inpatients and outpatients and health examiners who attended a hospital from March 2018 to March 2020. All patients in the CMS group lived in areas above 2500 meters above sea level for a long time. They were diagnosed according to the CMS diagnostic criteria recommended by the International Conference on High Altitude Medicine and Hypoxic Physiology, with a CMS score of $\geq 5$; healthy physical examiners and patients with simple fractures in areas with similar average altitudes as the control group.

Exclusion criteria-Except acute and chronic infections, chronic lung diseases, tumors, sleep apnea syndrome, immune-related diseases, polycythemia vera, myeloproliferative tumors, congenital heart disease and secondary polycythemia caused by other reasons, diseases and so on.

Collection of peripheral blood and bone marrow fluid: All study subjects collected specimens from high altitude areas to Xining within $1 \mathrm{w}$ and collected $2 \mathrm{ml}$ of peripheral venous blood in the early morning on an empty stomach for peripheral blood cytology analysis and at the same time, took $2 \mathrm{ml}$ of arterial blood for blood gas analysis. For bone marrow sampling, 1-2 cm of the posterior superior iliac spine was selected as the puncture point. After disinfection, the bone marrow puncture needle was used to extract $0.1-0.2 \mathrm{ml}$ of bone marrow fluid and place it on a glass slide to prepare 5-6 smears for cell morphology observation. Then aspirate $5-10 \mathrm{ml}$ of bone marrow fluid and put them into separate vacuum tubes for flow detection.

Experimental materials: Ficoll lymphocyte separation solution was purchased from Sigma, USA; Glycophorin A (CD235a) antibody magnetic beads were purchased from Miltenyi, Germany; Anti-human CD235a monoclonal antibody, Annexin V/Propidium Iodide (PI) kit, tetraethylbenzimidazolylcarbocyanine iodide (JC-1), MMP detection kit, mouse anti-human TNFR monoclonal antibody, rabbit anti-human FAS monoclonal antibody, anti-human caspase-3 monoclonal antibody, fixation/rupture kit purchased from Becton, Dickinson and company (BD) in the United States; immune anti-human Bax monoclonal antibody, rabbit anti-human Bcl-2 monoclonal antibody, Rabbit anti-human cytochrome c (cyt c) monoclonal antibody, isotype control antibody was purchased from BioLegend in the United States; Total RNA isolation reagent (TRizol) was purchased from Thermo Fisher Scientific (China) Co., Ltd.; isopropanol and absolute ethanol were purchased from Tianjin; agarose was purchased from UltraPure Company; Polymerase Chain Reaction (PCR) primer synthesis was purchased from Qiagen, Germany; reverse transcription kit was purchased, quantitative PCR (qPCR) and Carbonyl Cyanide 3-Chlorophenylhydrazone (CCCP) cell apoptosis inducer $(50 \mathrm{mM})$ were purchased from Beijing.

\section{Method:}

Isolation of BMMNCs by density gradient centrifugation: Collect 5-10 $\mathrm{ml}$ of bone marrow fluid of the subject with an anticoagulation tube containing Ethylenediamine Tetraacetic Acid (EDTA); centrifuge the bone marrow fluid at $1500 \mathrm{rpm} / \mathrm{min}$ for $5 \mathrm{~min}$ at room temperature and discard the upper plasma; add an equal volume of $1 \times$ Phosphate Buffered Saline (PBS) to 
the remaining pelleted bone marrow fluid and mix well for proper dilution; slowly add the above suspension along the tube wall to the surface of the same volume of Ficoll lymphocyte separation liquid, place it in a horizontal centrifuge at $2000 \mathrm{rpm} / \mathrm{min}$ and centrifuge for $20 \mathrm{~min}$ at room temperature; after centrifugation, the centrifuge tube will go from top to bottom. It is divided into four layers: dilution liquid layer, milky white mononuclear cell layer, separation liquid layer and red blood cell layer. Carefully pipette the mononuclear cell layer into another centrifuge tube, centrifuge at 1500 $\mathrm{rpm} / \mathrm{min}$ at room temperature for $5 \mathrm{~min}$, discard the supernatant; wash the cells twice with $10 \mathrm{ml}$ of $1 \times$ PBS; resuspend the cell pellet in $5 \mathrm{ml}$ of $1 \times$ PBS. Add $10 \mu \mathrm{l}$ of the above cell suspension to $990 \mu$ of $1 \times$ PBS, mix well and count the cells for the next experiment.

Separate bone marrow CD235a+ nucleated red blood cells with immunomagnetic beads: Count the BMMNCs obtained by the above density gradient centrifugation method; centrifuge at $1500 \mathrm{rpm} / \mathrm{min}$ for $10 \mathrm{~min}$, discard the supernatant and resuspend every $10^{7}$ cells in $80 \mu \mathrm{l}$ buffer; add $20 \mu \mathrm{l}$ CD235a antibody magnetic beads to every $10^{7}$ cells, incubate in the dark at $4^{\circ}$ for $15 \mathrm{~min}$; after the incubation, add $5 \mathrm{ml}$ buffer solution, centrifuge at $1500 \mathrm{rpm} / \mathrm{min}$ for $10 \mathrm{~min}$ and discard the supernatant; add $500 \mu \mathrm{l}$ buffer solution to every $10^{8}$ cells, pipette and mix well, prepare for magnetic bead sorting; place the LS sorting column, enter the sorting magnetic field, first use $3 \mathrm{ml}$ buffer to pass through the sorting column to make it fully wet for use; put the above cell suspension into the sorting column, after the liquid completely passes through the sorting column, rinse the sorting column 3 times with $3 \mathrm{ml}$ buffer respectively, discard the outflowing liquid; take the sorting column out of the magnetic field, add $5 \mathrm{ml}$ buffer to the column, use a piston to quickly flush it into a $15 \mathrm{ml}$ centrifuge tube, then collected CD235a+ cells and parallel cell counting.

Flow cytometry detection of bone marrow CD235a+ nucleated red blood cell apoptosis rate: Adjust the cell concentration of the above BMMNCs to $1 \times 10^{6}$ cells $/ \mathrm{ml}$ and take $100 \mu \mathrm{l}\left(1 \times 10^{5}\right.$ cells $)$ into a flow tube; add $10 \mu \mathrm{l}$ Allophycocyanin (APC) labeled CD235a monoclonal antibody and incubate for $15 \mathrm{~min}$ at room temperature in the dark; wash the cells with $3 \mathrm{ml} 1 \times$ binding buffer solution, then add $5 \mu \mathrm{l}$ AnnexinV-Fluorescein Isothiocyanate (FITC) and incubate for $15 \mathrm{~min}$ at room temperature in the dark; add $5 \mu \mathrm{PI}$ and incubate in the dark at room temperature for 5 min; add $400 \mu \mathrm{l}$ $1 \times$ binding buffer solution, test on the machine within
$24 \mathrm{~h}$ after mixing, confirm 20000 cells BMMNCs, to determine the ratio of CD235a+ cell apoptosis.

Flow cytometry to detect the MMP of bone marrow CD235a+ nucleated red blood cells: Prepare $1 \times$ assay buffer and JC-1 working solution according to JC-1 MMP detection kit; prepare $1 \times 10^{6} / \mathrm{ml}$ suspension from bone marrow CD235a+ nucleated erythrocytes after immunomagnetic bead sorting and reserve one set of cells induced by CCCP for 20 min was used as a positive control; after the induction of apoptosis, the above cells were centrifuged at $2000 \mathrm{rpm} \times 5 \mathrm{~min}$ and the supernatant was discarded; $0.5 \mathrm{ml} \mathrm{JC}-1$ was added to each Eppendorf (EP) tube to work; mix the cells and working solution thoroughly and then incubate them in a $37^{\circ}$ water bath for $15 \mathrm{~min}$; after the incubation, transfer the sample to a $15 \mathrm{ml}$ centrifuge tube, add 2 $\mathrm{ml} 1 \times$ assay buffer to each tube and gently pipette to disperse the cells completely. Centrifuge at $2000 \mathrm{rpm} \times 5$ $\mathrm{min}$ at room temperature, discard the supernatant; add $1 \mathrm{ml}$ of $1 \times$ assay buffer to each tube and repeat the step that is transfer the sample to a $15 \mathrm{ml}$ centrifuge tube, add $2 \mathrm{ml} 1 \times$ assay buffer to each tube and gently pipette to disperse the cells completely; add $0.5 \mathrm{ml} 1 \times$ assay buffer to each tube, shake the cells gently and test on the machine.

qPCR detection of bone marrow CD235a+ nucleated red blood cell apoptosis related gene messenger RNA (mRNA) expression: In qPCR reaction, the primers were all synthesized by Qiagen, Glyceraldehyde 3-Phosphate Dehydrogenase (GAPDH) was used as the internal control and $20 \mu \mathrm{l}$ was prepared according to the Tiangen super real fluorescence quantitative kit. Reaction system $(20 \mu \mathrm{l})$ : Complementary DNA (cDNA) template $2 \mu \mathrm{l}$, super real premix plus $10 \mu \mathrm{l}$, primer mix $0.6 \mu 1$, 6-carboxy-X-rhodamine (ROX) reference dye $0.4 \mu \mathrm{l}$, ribonuclease (RNase) free double distilled water $\left(\mathrm{ddH}_{2} \mathrm{O}\right) 7 \mu \mathrm{l}$; carry out the $\mathrm{qPCR}$ reaction as follows: $95^{\circ} 15 \mathrm{~min} ; 95^{\circ} 10 \mathrm{~s} ; 60^{\circ} 32 \mathrm{~s}$. Optimize the qPCR reaction: Dilute the template cDNA to different concentration gradients for qPCR reaction, use this result to make a standard curve and then use the optimal cDNA concentration for the later qPCR reaction. Analysis of qPCR results: refer to the calculation formula deduced by Livak, etc., and use the relative quantification method to calculate the expression level of the target gene to accurately obtain the expression of the target gene in the CMS group and the control group, according to the $\Delta \mathrm{CT}$ of the sample and internal control, $2^{-\Delta \Delta C \mathrm{~T}}$ statistical data. 
Western blot detection of bone marrow CD235a+ nucleated red blood cell apoptosis related protein expression: The cells were lysed with Radioimmunoprecipitation Assay (RIPA) buffer to prepare total protein and then quantified using the bicinchoninic acid assay (BCA) protein kit. Then, the same amount of protein was separated by a $12 \%$ Sodium Dodecyl Sulphate (SDS) polyacrylamide gel and transferred to a Polyvinylidene Fluoride (PVDF) membrane. The membrane was incubated with $5 \%$ skim milk to block non-specific binding. Then, treat the membrane with the primary antibody. The concentration of the primary antibody is used according to the instructions, which is usually between 1:500-1:2000 and then incubate overnight. After further incubation with the horseradish peroxidase-labeled secondary antibody, the Enhanced Chemiluminescence (ECL) detection kit was used to display the immunoreactive bands and the quantitative density analysis of the protein bands was performed by Image J software.

\section{Statistical methods:}

Statistical Package For The Social Sciences (SPSS) 25.0 statistical software was used for analysis. The data were all measurement data. All experimental data are tested for normality and they are all normally distributed. The results are expressed as mean \pm standard deviation $(\mathrm{x} \pm \mathrm{s})$. The independent sample $t$ test is used for comparison between the two groups. The correlation analysis between indicators adopts linear correlation analysis. Inspection level $\alpha=0.05$.

\section{RESULTS AND DISCUSSION}

The subjects of the study were 21 CMS patients and 20 controls. The two groups had no significant differences in age, height and Body Mass Index (BMI). Compared with the control group, the hemoglobin and hematocrit of the CMS group were significantly increased $(p<0.01)$, while the blood arterial oxygen saturation $\left(\mathrm{SaO}_{2}\right)$ was significantly decreased $(\mathrm{p}<0.01)$. The CMS score of CMS patients was 8-17 points. The general information of the two groups of research subjects is shown in Table 1.

Flow cytometry determined the apoptotic rate of bone marrow erythrocytes in $21 \mathrm{CMS}$ patients and 20 controls (fig. 1). The apoptotic rate of CMS bone marrow $\mathrm{CD} 235 \mathrm{a}+$ nucleated erythrocytes was $(5.41 \pm 2.11) \%$ and the control group was $(7.25 \pm 2.24) \%$, the difference between the two groups was statistically significant $(\mathrm{t}=2.18, \mathrm{p}<0.05)$.

Changes in the MMP of bone marrow CD235a+ nucleated red blood cells were determined. Flow cytometry measured 21 cases of CMS patients and 20 cases of control bone marrow CD235a + nucleated red blood cell MMP (fig. 2). The CMS group bone marrow $\mathrm{CD} 235 \mathrm{a}+$ nucleated red blood cell JC-1 staining green fluorescence ratio was $(3.43 \pm 1.88) \%$ and the control group was $(5.25 \pm 3.26) \%$, the difference between the two groups was statistically significant $(\mathrm{t}=2.36, \mathrm{p}<0.05)$.

The mRNA expression levels of apoptosis pathway related genes in 21 cases of CMS patients and 20 cases of control bone marrow nucleated erythrocytes were determined by qPCR technology. The results showed that there was no significant difference between the CMS group and the control group in the expression of $\mathrm{CD} 235 \mathrm{a}+$ nucleated erythrocyte cyt $\mathrm{c}$ mRNA ( $>>0.05)$. The level of Bax mRNA in CD235a+ nucleated red blood cells in the CMS group was lower than that in the control group, while caspase-3, Mcl-1, Bcl-2 and Bcl$\mathrm{xl}$ were higher than those in the control group $(\mathrm{p}<0.05)$ (Table 2 and fig. 3).

TABLE 1: GENERAL CLINICAL CHARACTERISTICS OF THE STUDY SUBJECTS

\begin{tabular}{lcccc}
\hline Variable & Control group $(\mathrm{n}=21)$ & CMS group $(\mathrm{n}=20)$ & Statistical value & $\mathrm{p}$ \\
\hline Age $(\mathrm{y})$ & $41.73 \pm 5.78$ & $41.60 \pm 4.56$ & $\mathrm{t}=-0.89$ & 0.93 \\
Height $(\mathrm{cm})$ & $169.95 \pm 5.70$ & $170.86 \pm 4.85$ & $\mathrm{t}=1.13$ & 0.26 \\
BMI $\left(\mathrm{kg} / \mathrm{m}^{2}\right)$ & $23.86 \pm 3.98$ & $23.98 \pm 3.37$ & $\mathrm{t}=0.11$ & 0.92 \\
Hemoglobin $(\mathrm{g} / \mathrm{l})$ & $145.79 \pm 9.52$ & $216.06 \pm 10.87$ & $\mathrm{t}=21.91$ & 0.00 \\
Hematocrit $(\%)$ & $40.64 \pm 2.12$ & $65.23 \pm 2.72$ & $\mathrm{t}=32.17$ & 0.00 \\
Red blood cell count & $4.68 \pm 0.37$ & $6.37 \pm 0.35$ & $\mathrm{t}=15.36$ & 0.00 \\
$\left(10^{12} / \mathrm{l}\right)$ & $93.17 \pm 2.06$ & $82.65 \pm 1.52$ & $\mathrm{t}=-18.62$ & 0.00 \\
Saturation $(\%)$ & $2(0-4)$ & $11(8-16)$ & $\mathrm{t}=-12.83$ & 0.00 \\
CMS integration & &
\end{tabular}



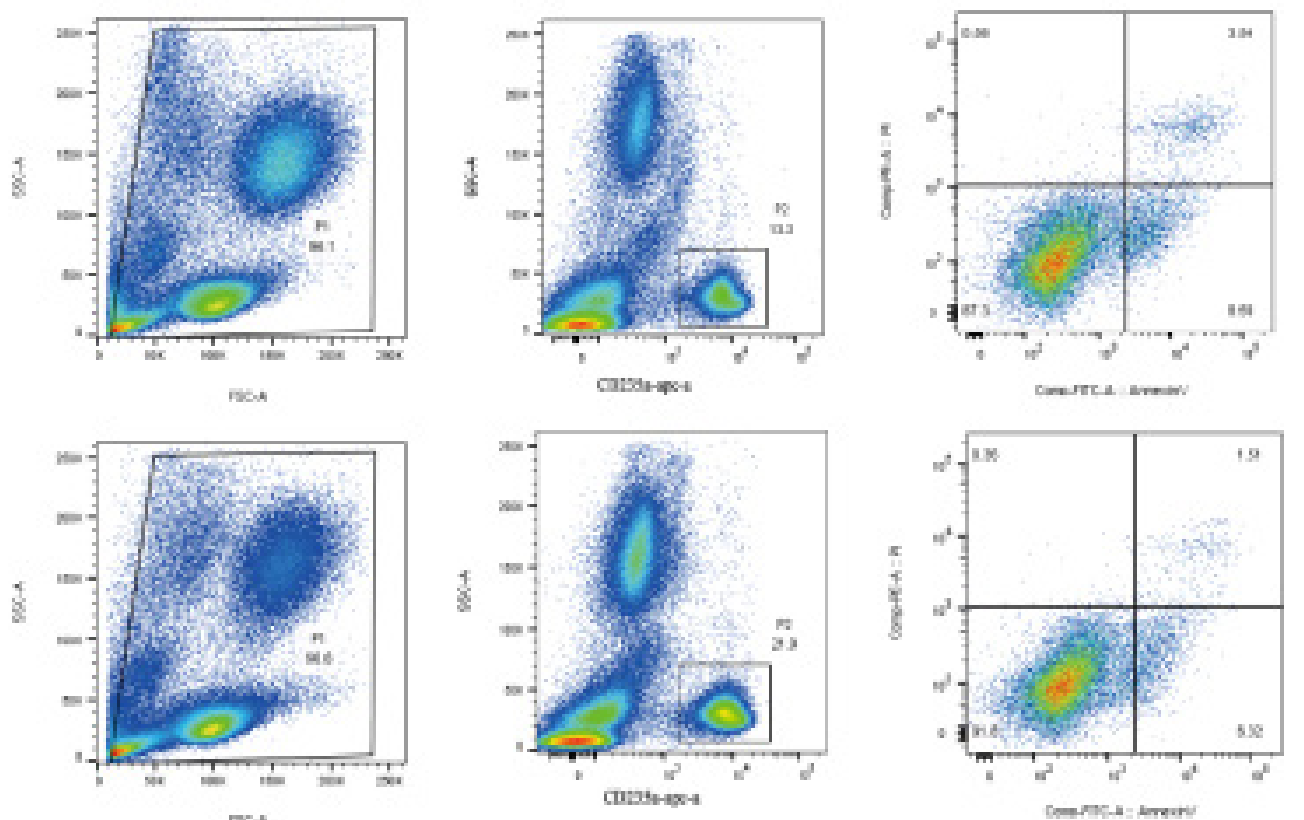

nas

Comen:- inew

Fig. 1: Determination of the apoptosis rate of CD235a+ erythroblasts in bone marrow of CMS group and control group by flow cytometry
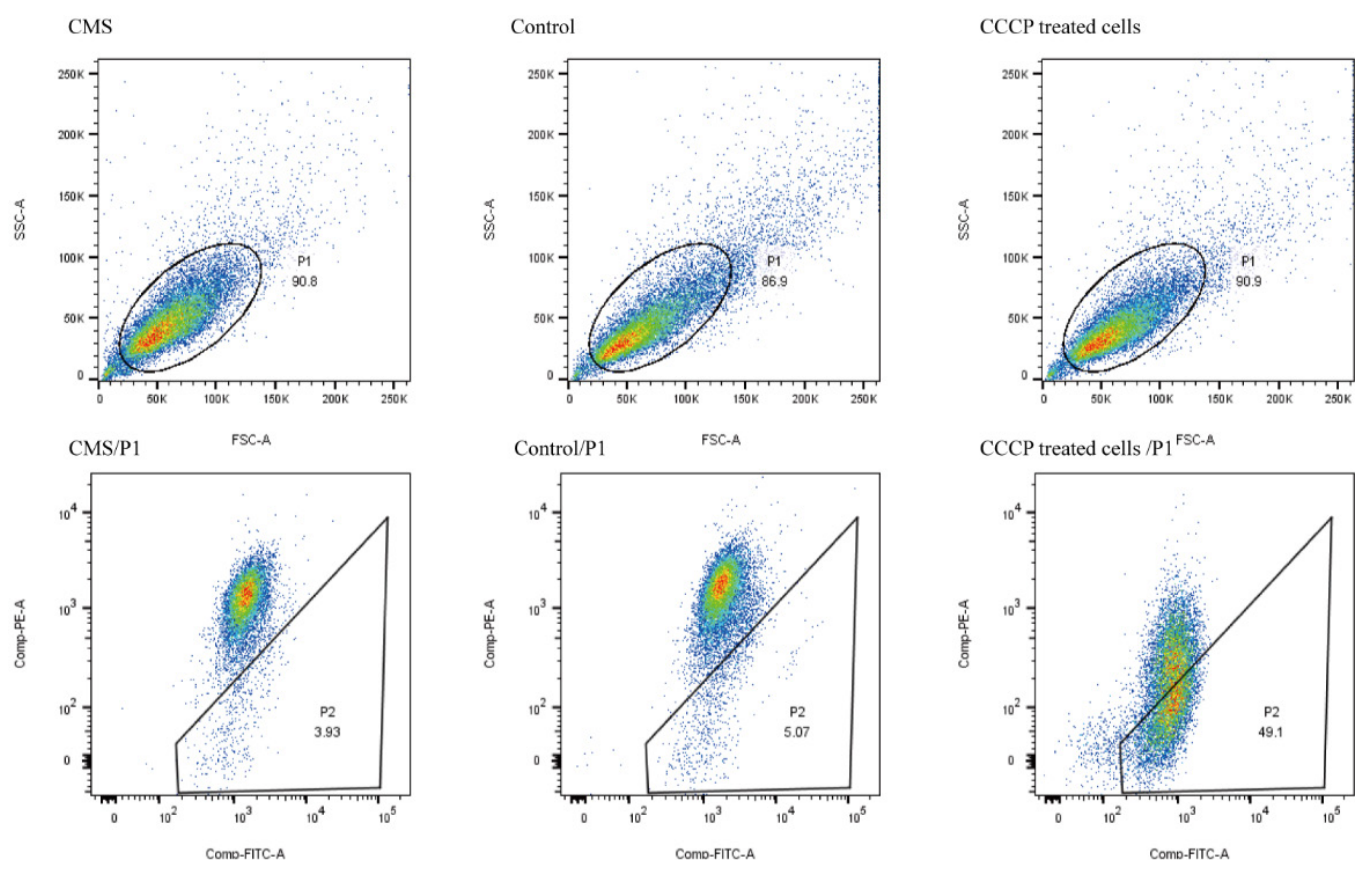

Fig. 2: Determination of MMP of CD235a+ erythroblasts in CMS group and control group by flow cytometry

TABLE 2: RELATIVE MRNA LEVELS OF APOPTOSIS RELATED GENES IN BONE MARROW CD235a+ ERYTHROBLASTS OF CMS GROUP AND CONTROL GROUP

\begin{tabular}{lccccccc}
\hline \multirow{2}{*}{ Grouping } & \multirow{2}{*}{ Quantity } & \multicolumn{7}{c}{ mRNA } \\
\cline { 2 - 7 } & & Cyt c & Caspase-3 & Mcl-1 & Bcl-2 & Bax & Bcl-xl \\
\hline CMS group & 21 & $1.19 \pm 0.18$ & $1.51 \pm 0.41$ & $1.83 \pm 0.52$ & $1.57 \pm 0.36$ & $0.88 \pm 0.23$ & $1.68 \pm 0.43$ \\
Control group & 20 & $1.11 \pm 0.16$ & $1.03 \pm 0.48$ & $1.22 \pm 0.59$ & $1.12 \pm 0.42$ & $1.21 \pm 0.39$ & $0.52 \pm 0.18$ \\
$\mathrm{t}$ & & -0.68 & 6.03 & 5.44 & 4.24 & -6.67 & 15.74 \\
$\mathrm{p}$ & & 0.50 & 0.00 & 0.00 & 0.00 & 0.00 & 0.00 \\
\hline
\end{tabular}



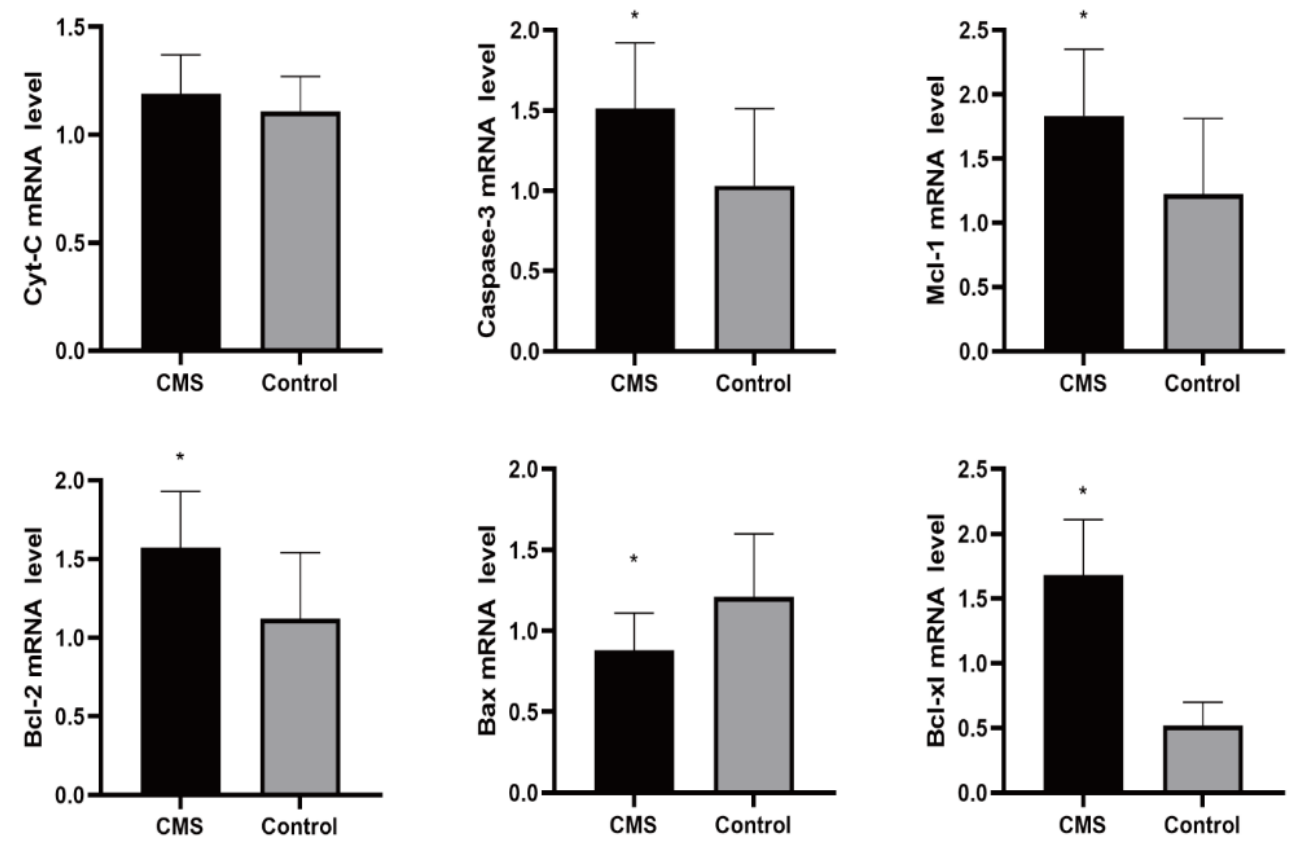

Fig. 3: Relative mRNA levels of apoptosis-related genes in bone marrow CD235a+ erythroblasts of CMS group and control group $\left({ }^{*} \mathbf{p}<0.05\right)$

In order to confirm that the reduction of CMS bone marrow nucleated red blood cell apoptosis in the above qPCR experiment is related to the expression changes of mitochondrial pathway-related genes, western blot technology was used to detect and quantitatively analyze CD235a+ cells stained with the corresponding antibodies. The results showed that the protein level of cyt $\mathrm{c}$ in bone marrow $\mathrm{CD} 235 \mathrm{a}+$ cells was not significantly different between the two groups $(\mathrm{p}>0.05)$, while the protein level of Bax in the CMS group was significantly lower than that in the control group $(\mathrm{p}<0.05)$, caspase-3, Mcl-1. The protein levels of $\mathrm{Bcl}-2$ and Bcl-xl were significantly higher than those of the control group $(\mathrm{p}<0.05)$ and the expression levels of apoptosis-related proteins were consistent with their mRNA expression levels (Table 3 and fig. 4).
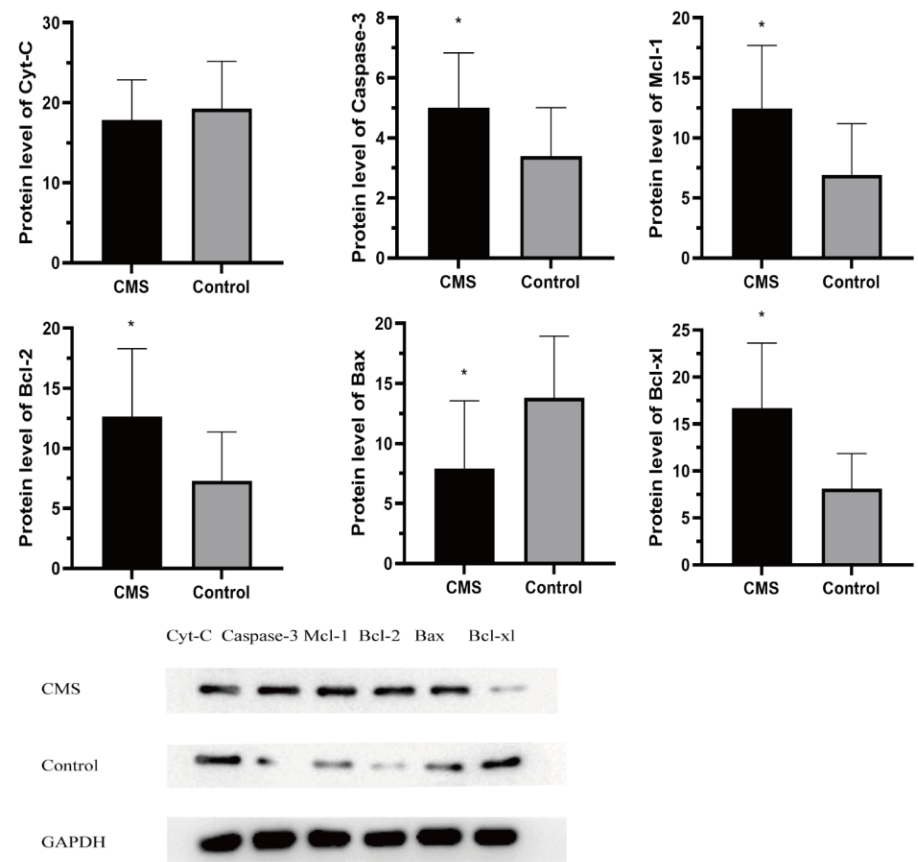

Fig. 4: Expression levels of apoptosis-related proteins in bone marrow CD235a+ erythroblasts of CMS group and control group $(* p<0.05)$ 
TABLE 3: EXPRESSION LEVELS OF APOPTOSIS RELATED PROTEINS IN BONE MARROW CD235a+ ERYTHROBLASTS OF CMS GROUP AND CONTROL GROUP

\begin{tabular}{lccccccc}
\hline \multirow{2}{*}{ Grouping } & \multirow{2}{*}{ Quantity } & \multicolumn{7}{c}{ Protein } \\
\cline { 3 - 7 } & & Cyt c & Caspase-3 & Mcl-1 & Bcl-2 & Bax & Bcl-xl \\
\hline CMS Group & 21 & $17.87 \pm 5.01$ & $5.01 \pm 1.82$ & $12.44 \pm 5.27$ & $12.66 \pm 5.63$ & $7.92 \pm 4.36$ & $16.68 \pm 6.93$ \\
Control group & 20 & $19.26 \pm 5.93$ & $3.39 \pm 1.62$ & $6.93 \pm 4.25$ & $7.30 \pm 4.07$ & $13.81 \pm 5.13$ & $8.09 \pm 3.76$ \\
$\mathrm{t}$ & & -0.65 & 2.68 & 7.09 & 5.35 & -7.78 & 8.42 \\
$\mathrm{p}$ & & 0.52 & 0.01 & 0.00 & 0.00 & 0.00 & 0.00 \\
\hline
\end{tabular}

The body's cell metabolism is in a dynamic equilibrium state. When the red blood cells of CMS patients are excessively increased, it is the result of the imbalance of red blood cell production and death. So how about the death of erythroid cells in CMS patients? Generally speaking, while erythroid proliferation is enhanced, if apoptosis is up-regulated, it will delay or reduce the occurrence and development of CMS; if apoptosis is down-regulated, it will have a certain promoting effect in the occurrence and development of CMS. But so far, there are few in-depth research reports on the apoptosis of CMS bone marrow erythroid nucleated cells and its mechanism at home and abroad. In this study, flow cytometry was used to directly measure the apoptosis of bone marrow CD235a+ erythroid erythrocytes in CMS patients. The study found that the apoptosis rate of bone marrow CD235a+ erythroid nucleated cells in CMS patients was lower than that in the control group, suggesting that the apoptosis of bone marrow erythroid cells in CMS patients was reduced. There is an imbalance between birth and death. Studies have shown that the mitochondrial pathway is an important mechanism for down-regulation of erythroid precursor cell apoptosis in patients with CMS, including caspasedependent and caspase-independent pathways ${ }^{[18-21]}$. In this study, the expression of molecules related to the caspase-dependent apoptosis pathway in bone marrow $\mathrm{CD} 235 \mathrm{a}+$ nucleated erythrocytes of CMS patients was systematically investigated. The results showed that the protein level of cyt $\mathrm{c}$ in bone marrow CD235a+ cells was not significantly different between the two groups ( $>0.05$ ), while the protein level of Bax in the CMS group was significantly lower than that in the control group ( $\mathrm{p}<0.05$ ), caspase-3, Mcl-1. The protein levels of $\mathrm{Bcl}-2$ and Bcl-xl were significantly higher than those of the control group $(\mathrm{p}<0.05)$ and the expression levels of apoptosis-related mRNA were consistent with the expression levels of related proteins. At the same time, the MMP of bone marrow CD235a+ nucleated red blood cells of CMS patients is higher than that of the control group. These studies indicate that the mitochondrial pathway plays a very important role in the pathogenesis of down-regulation of bone marrow nucleated red blood cell apoptosis in CMS patients. Studies have shown that changes in MMP play an important role in the process of apoptosis ${ }^{[2]}$. When the mitochondria receives the apoptosis signal and then releases the pro-apoptotic factors, the MMP continues to decrease, indicating that the cell has undergone apoptosis ${ }^{[23]}$. The results of this study suggest that bone marrow CD235a + nucleated red blood cell apoptosis in CMS patients is related to changes in MMP and the release of apoptotic proteins.

Priti Azad and other studies also found that the expression of the anti-apoptotic gene Bcl-xl was significantly increased in patients with $\mathrm{CMS}^{[24]}$. At present, there are few domestic and foreign studies on the mechanism of apoptosis of nucleated red blood cells in the bone marrow of CMS patients. In this study, the expression of anti-apoptotic proteins Bcl-2 and Mcl-1 increased, indicating that the hypoxic state of the body will also increase at the same time. The hypoxia of the bone marrow hematopoietic microenvironment has also shown that Hypoxia-Inducible Factor 1-alpha (HIF$1 \alpha$ ) is also involved in cell apoptosis in the hypoxic environment ${ }^{[25,26]}$. Studies have also shown that HIF-1 $\alpha$ inhibits apoptosis by reducing the expression of $\mathrm{Bax}^{[27,28]}$. In addition, studies have shown that EPO activates Signal Transducer And Activator Of Transcription 5 (STAT5), Phosphatidylinositol 3-Kinase (PI3K)/protein kinase $\mathrm{B}(\mathrm{Akt})$ and other pathways through Janus Kinase 2 (JAK2), thereby reducing cell apoptosis ${ }^{[2,30]}$. Therefore, the changes in some molecules of the Bcl-2 family of CD235a+ nucleated red blood cells in CMS patients may also be related to the increase of EPO. This study also has inadequacies and fails to clarify the molecular mechanism and signaling pathways of the effects of hypoxia on bone marrow nucleated red blood cells and even other cells.

In this study, CMS patients and healthy people in the same altitude area were used as the research objects to study the apoptosis of bone marrow nucleated red blood 
cells and the changes of factors related to the apoptosis pathway in CMS patients. Studies have shown that the proliferation of bone marrow nucleated erythrocytes in CMS patients is enhanced and apoptosis is decreased and both have a certain correlation with Hemoglobin $\mathrm{Hb})$ level. There is a synergistic effect between the two. At the same time, the expression of Bax in bone marrow nucleated erythrocytes of CMS patient's decreases and the expressions of Bcl-2, Bcl-xl and Mcl-1 are elevated, indicating that the mitochondrial pathway is one of the important mechanisms for the down-regulation of CMS nucleated red blood cell apoptosis.

\section{Acknowledgments:}

Yuanbin Yao and Yanmin Liu equally contribute to this work

\section{Funding:}

The work was supported by Guiding project of Qinghai Health Commission (2019-wjzdx-35) and Qinghai Province Science and technology plan project in 2018 and Innovation Platform Construction project of Qinghai Department of Science and Technology in 2019 (ID:2019-SF-L1) (2018-sf-114)

\section{Conflicts of interest:}

The authors declared no conflict of interest.

\section{REFERENCES}

1. Liu H, Tang F, Su J, Ma J, Qin Y, Ji L, et al. EPAS1 regulates proliferation of erythroblasts in chronic mountain sickness. Blood Cells Mol Dis 2020;84:102446.

2. Villafuerte FC, Corante N. Chronic mountain sickness: clinical aspects, etiology, management, and treatment. High Alt Med Biol 2016;17(2):61-9.

3. Sanchez-Mascunano A, Masuet-Aumatell C, Morchon-Ramos S, Ramon JM. Relationship of altitude mountain sickness and smoking: a Catalan traveller's cohort study. BMJ Open 2017;7(9):e017058.

4. Bailey DM, Brugniaux JV, Filipponi T, Marley CJ, Stacey B, Soria R, et al. Exaggerated systemic oxidativeinflammatory-nitrosative stress in chronic mountain sickness is associated with cognitive decline and depression. J Physiol 2019;597(2):611-29.

5. Bermudez D, Azad P, Figueroa-Mujíca R, Vizcardo-Galindo G, Corante N, Guerra-Giraldez C, et al. Increased hypoxic proliferative response and gene expression in erythroid progenitor cells of Andean highlanders with chronic mountain sickness. Am J Physiol Regul Integr Comp Physiol 2020;318(1):R49-56.

6. Villafuerte FC, Corante N, Anza-Ramírez C, Figueroa-Mujíca R, Vizcardo-Galindo G, Mercado A, et al. Plasma soluble erythropoietin receptor is decreased during sleep in Andean highlanders with chronic mountain sickness. J Appl Physiol 2016;121(1):53-8.
7. Yang M, Zhu M, Song K, Wuren T, Yan J, Ge RL, et al. VHL gene methylation contributes to excessive erythrocytosis in chronic mountain sickness rat model by upregulating the HIF2 $\alpha$ /EPO pathway. Life Sci 2021;266:118873.

8. Ma J, Ji L, Li Z, Liu H, Zhao C, Xiong H, et al. Downregulation of intrinsic apoptosis pathway in erythroblasts contributes to excessive erythrocytosis of chronic mountain sickness. Blood Cells Mol Dis 2019;76:25-31.

9. Zhao C, Li Z, Ji L, Ma J, Ge RL, Cui S. PI3K-Akt signal transduction molecules maybe involved in downregulation of erythroblasts apoptosis and perifosine increased its apoptosis in chronic mountain sickness. Med Sci Monit 2017;23:5637.

10. Liu S, Zhu Y, Yan S, Xiao H, Yi J, Li R, et al. Phenethyl isothiocyanate induces IPEC-J2 cells cytotoxicity and apoptosis via $\mathrm{S}-\mathrm{G} 2 / \mathrm{M}$ phase arrest and mitochondria-mediated Bax/Bcl-2 pathway. Comp Biochem Physiol Part C Toxicol Pharmacol 2019;226:108574.

11. Pandey S, Patil S, Ballav N, Basu S. Spatial targeting of Bcl-2 on endoplasmic reticulum and mitochondria in cancer cells by lipid nanoparticles. J Mater Chem B 2020;8(19):4259-66.

12. Bessou M, Lopez J, Gadet R, Deygas M, Popgeorgiev N, Poncet $\mathrm{D}$, et al. The apoptosis inhibitor Bcl-xL controls breast cancer cell migration through mitochondria-dependent reactive oxygen species production. Oncogene 2020;39(15):3056-74.

13. Singh PK, Roukounakis A, Frank DO, Kirschnek S, Das KK, Neumann S, et al. Dynein light chain 1 induces assembly of large Bim complexes on mitochondria that stabilize Mcl-1 and regulate apoptosis. Genes Dev 2017;31(17):1754-69.

14. Patel R, Baker SS, Liu W, Desai S, Alkhouri R, Kozielski R, et al. Effect of dietary advanced glycation end products on mouse liver. PLoS One 2012;7(4):e35143.

15. Wang W, Zhu M, Xu Z, Li W, Dong X, Chen Y, et al. Ropivacaine promotes apoptosis of hepatocellular carcinoma cells through damaging mitochondria and activating caspase-3 activity. Biol Res 2019;52(1):1-10.

16. Kassab AE, Gedawy EM. Novel ciprofloxacin hybrids using biology oriented drug synthesis (BIODS) approach: anticancer activity, effects on cell cycle profile, caspase-3 mediated apoptosis, topoisomerase II inhibition, and antibacterial activity. Eur J Med Chem 2018;150:403-18.

17. Li X, Fang F, Gao Y, Tang G, Xu W, Wang Y, et al. ROS induced by Killer Red targeting mitochondria (mtKR) enhances apoptosis caused by radiation via Cyt c/caspase-3 pathway. Oxid Med Cell Longev 2019;2019.

18. Cai J, Wu X, Li X, Ma C, Xu L, Guo X, et al. Allicin protects against cisplatin-induced stria vascularis damage: Possible relation to inhibition of caspase-3 and PARP-1-AIF-mediated apoptotic pathways. ORL J Otorhinolaryngol Relat Spec 2019;81(4):202-14.

19. Zhao W, Li H, Hou Y, Jin Y, Zhang L. Combined administration of poly-ADP-ribose polymerase-1 and caspase-3 inhibitors alleviates neuronal apoptosis after spinal cord injury in rats. World Neurosurg 2019;127:e346-52.

20. Guo W, Zhang Y, Ling Z, Liu X, Zhao X, Yuan Z, et al. Caspase-3 feedback loop enhances Bid-induced AIF/endoG and Bak activation in Bax and p53-independent manner. Cell Death Dis 2015;6(10):e1919.

21. Hu WL, Dong HY, Li Y, Ojcius DM, Li SJ, Yan J. Bid-induced release of AIF/EndoG from mitochondria causes apoptosis of macrophages during infection with Leptospira interrogans. 
Front Cell Infect Microbiol 2017;7:471.

22. Yu Z, Tian X, Peng Y, Sun Z, Wang C, Tang N, et al. Mitochondrial cytochrome P450 (CYP) 1B1 is responsible for melatonin-induced apoptosis in neural cancer cells. J Pineal Res 2018;65(1):e12478.

23. Wang TS, Coppens I, Saorin A, Brady NR, Hamacher-Brady A. Endolysosomal targeting of mitochondria is integral to BAXMediated mitochondrial permeabilization during apoptosis signaling. Dev Cell 2020;53(6):627-45.

24. Azad P, Zhao HW, Cabrales PJ, Ronen R, Zhou D, Poulsen $\mathrm{O}$, et al. Senp1 drives hypoxia-induced polycythemia via GATA1 and Bcl-xL in subjects with Monge's diseaseSENP1: Erythropoietic dysfunction at high altitude. J Exp Med 2016;213(12):2729-44.

25. Yin J, Ni B, Liao WG, Gao YQ. Hypoxia-induced apoptosis of mouse spermatocytes is mediated by HIF-1 $\alpha$ through a death receptor pathway and a mitochondrial pathway. J Cell Physiol 2018;233(2):1146-55.

26. Karagiota A, Kourti M, Simos G, Mylonis I. HIF-1 $\alpha$-derived cell-penetrating peptides inhibit ERK-dependent activation of HIF-1 and trigger apoptosis of cancer cells under hypoxia. Cell Mol Life Sci 2019;76(4):809-25.

27. Dong Y, Wang J, Du KX, Jia TM, Zhu CL, Zhang Y, et al. MicroRNA-135a participates in the development of astrocytes derived from bacterial meningitis by downregulating HIF-1 $\alpha$. Am J Physiol Cell Physiol 2019;316(5):C711-21.
28. Peng K, Chen WR, Xia F, Liu H, Meng XW, Zhang J, et al. Dexmedetomidine post-treatment attenuates cardiac ischaemia/reperfusion injury by inhibiting apoptosis through HIF-1 $\alpha$ signalling. J Cell Mol Med 2020;24(1):850-61.

29. Chen GZ, Dai WS, Zhu HC, Song HM, Yang X, Wang YD, et al. Foretinib enhances the radiosensitivity in esophageal squamous cell carcinoma by inhibiting phosphorylation of c-Met. J Cancer 2017;8(6):983.

30. Huang H, Zhang H, Li D, Chen S, Zhou C, Li Q, et al. Different inhibitory effects on the proliferation and apoptosis of human and laboratory Borna disease virus-infected human neuroblastoma SH-SY5Y cells in vitro. Mol Med Rep 2018;17(1):925-31.

This is an open access article distributed under the terms of the Creative Commons Attribution-NonCommercial-ShareAlike 3.0 License, which allows others to remix, tweak, and build upon the work non-commercially, as long as the author is credited and the new creations are licensed under the identical terms

This article was originally published in a special issue, "Diagnostic and Therapeutic Advances in Biomedical Research and Pharmaceutical Sciences"

Indian J Pharm Sci 2021:83(5) spl issue "119-127" 